\title{
Polyomavirus in Renal Transplantation: A Hot Problem
}

\author{
Catherine Bonvoisin, Laurent Weekers, Patricia Xhignesse, Stéphanie Grosch, Miroslav Milicevic, \\ and Jean-Marie Krzesinski
}

\begin{abstract}
Polyomavirus BK has emerged as an important complication after kidney transplantation. Although, BK nephropathy develops in only $1 \%$ to $5 \%$ of renal transplant recipients, its prognosis when present is very poor. The most accepted risk factor is the level of immunosuppressive treatment, but the serostatus of donor and recipient and the absence of human leukocyte antigen $\mathrm{C} 7$ in donor and/or recipient influence the BK virus (BKV) reactivation. The gold standard in diagnosing BKV nephropathy (BKVN) continues to be biopsy with use of immunohistochemistry for large $\mathrm{T}$ antigens. Urinary decoy cells and blood BKV DNA polymerase chain reaction are used in the screening, but their positive predictive values are poor. However, their use as predictors of the evolution of BKVN is more valuable. The reduction of immunosuppressive therapy currently represents the first-line treatment for BKVN. Cidofovir and leflunomide can be used when BKVN continues to progress. In the event of graft loss, retransplantation is possible with a low risk of recurrence when the infection is no longer active.
\end{abstract}

Keywords: Renal transplantation, BK virus nephropathy, Decoy cell, Leflunomide, Cidofovir.

(Transplantation 2008;85: S42-S48)

$\mathrm{S}_{\mathrm{n}}^{\mathrm{in}}$ ince the 1990s, renal transplantation has become the treatment of choice for most patients with end-stage renal disease because of improvements in the quality of immunosuppression and a lower risk of mortality. Yet, some infectious diseases have appeared more often, leading to complications and making the choice of therapy more difficult. Human polyoma BK virus nephropathy $(\mathrm{BKVN})$ is one of these major clinical complications. It affects approximately $1 \%$ to $5 \%$ of kidney transplant recipients and may lead to irreversible graft failure in $45 \%$ of affected patients (1). The first case of polyoma virus infection in a kidney transplant patient was reported in 1971 (2). The virus was named $\mathrm{BK}$ virus owing to the initials of the first patient diagnosed with this infection.

During the era of cyclosporine-based immunosuppression, BKVN was of no real clinical significance. The use of new drugs such as tacrolimus and mycophenolate mofetil (MMF) has been proven to contribute to a reduction in the incidence of acute rejection episodes, but at the same time, many centers have noted a concomitant rise in the incidence of opportunistic infections caused by the BK virus (3-5).

\section{Virology}

Polyomavirus BK (BKV) has been classified in the Polyomaviridae family, which includes JC virus (JCV), simian virus 40 (SV40), and monkey polyomavirus. BKV and JCV are human pathogens with different infection outcomes: BKV causes nephritis and JCV is responsible for progressive multifocal leukoencephalopathy. Although both SV40 and JCV have been implicated in some cases of BKVN, most cases seem to be caused by BK virus. It has been suggested that SV40 and the monkey polyomavirus can also infect humans and may be related to the development of some human can-

\footnotetext{
The authors declare no potential conflicts of interest.

Department of Nephrology and Renal Transplantation, University Hospitals Liege, Belgium.

Address correspondence to: Catherine Bonvoisin, M.D., Department of Nephrology and Renal Transplantation, University Hospitals Liege, Hôpital du Sart-Tilman, Domaine Universitaire du Sart-Tilman, Bâtiment B35, B-4000 Liège, Belgium.

E-mail: catherine.bonvoisin@chu.ulg.ac.be

Copyright (C) 2008 by Lippincott Williams \& Wilkins

ISSN 0041-1337/08/8507S-42
}

DOI: $10.1097 /$ TP.0b013e318169c794 cers (6). Geetha et al. (7) have also reported a case of bladder carcinoma in a patient with BKVN in whom BKV was found in the bladder and the metastatic implant. These four viruses are very similar in structure, with DNA sequence homology. The polyomaviruses are a family of small, nonenveloped DNA viruses with icosahedral capsids of 40 to $44 \mathrm{~nm}$ in diameter. The viral genomes within the capsids are circular double-stranded DNA of 5300 base pairs, coated by host cell histones that encode the early regulatory and late structural proteins. The $\mathrm{BK}$ virus genome comprises the noncoding control region, the early-coding region coding for the small and large $\mathrm{T}$ antigens, and the late-coding region coding for the viral capsid proteins (VP1, VP2, and VP3) and agnoprotein (8). For the life-cycle of the virus to be completed, the virions must attach to the host cell plasma membrane through the binding of viral capsid proteins (likely in the VP-1 region) (9). After cell entry through caveola-mediated endocytosis, the BKV migrate through the cytoplasm/endoplasmatic reticulum/microtubules and the nuclear pores into the host cell nucleus. There, the uncoated mini-chromosome is transcribed. Transcription of the early genes results in the production of the $\mathrm{T}$ antigens that cause quiescent cells to re-enter the cell cycle and thus begin replication of cellular DNA. In permissive host cells, the T antigens, acting as regulatory proteins, conduct the remaining events, resulting in a productive infection. The completion of the process consists of viral DNA replication and transcription of late genes for the production of structural proteins (VP1, VP2, and VP3) that will constitute the capsid. Viral capsomeres assemble around the daughter minichromosomes in the nucleus, to form stable viral particles. Ultimately, host cells are lysed and mature daughter virions are released.

Primary infection with BKV typically occurs in early childhood with an adult seroprevalence rate of $80 \%(10,11)$. The natural route of transmission of BKV in the general population is incompletely understood, but multiple routes of infection are likely involved. Oral transmission through contaminated food or water has been suggested as a potential route of infection. Other potential routes include semen, blood products, organ transplantation (particularly renal allograft), and through the placenta (12). Thus, in infants with respiratory infections, BKV DNA has been amplified from $0 \%$ to $40 \%$ in urine samples and 
$1 \%$ in nasopharyngeal aspirates. The most frequent symptom associated with BKV primoinfection is an upper respiratory infection. Sporadic reports of acute cystitis, with or without hematuria, have also been reported. After primary infection has resolved, the virus enters a latency phase. This virus tends to persist indefinitely in different organs, including the kidney, ureters, brain, and lymphoid cells. Disease caused by the reactivation of latent polyomavirus is typically not seen in the immunocompetent host. However, slight changes in the immune status (during pregnancy, in patients suffering from diabetes mellitus, human immunodeficiency virus or cancer, and in recipients of renal or other allograft) can lead to transient, asymptomatic, and selflimiting viral activation, especially in the urothelium $(12,13)$.

\section{BK Nephropathy}

Reactivation of BKV can cause three different lesions in renal transplant recipients: hemorrhagic cystitis; urethral stenosis; and interstitial nephritis (14). Ahuja et al. (15) reported that reactivation may start as early as 4 months posttransplantation and run a course until graft failure, with a median diagnosis time of 9.5 months. Sachdeva et al. (16) reported that BKVN has been diagnosed as early as 6 days and as late as 6 years postgrafting. Serum creatinine levels vary from normal (early BKVN stage A) to markedly increased (late stages with marked injury, BKVN stages B and C). The most striking feature of $\mathrm{BK}$ infection in kidney transplant recipients is the lack of fever, malaise, myalgias, leukopenia, anemia, thrombocytopenia, or other symptoms or signs typical of viral infection. Thus, the clinician must consider this potential BKV infection in the face of renal function alteration. Reactivation of $\mathrm{BK}$ virus in renal transplant is very common during the first year posttransplantation with a prevalence of $45 \%$ to $50 \%$, but it leads only occasionally to BKVN.

Bressollette-Bodin et al. (17) demonstrated, in a prospective longitudinal study of BKV infection in 104 renal transplant recipients, the detection of BKV DNA (BKViruria) in the urine of a significant proportion of renal transplant recipients, with or without renal dysfunction. Detection of BKV DNA in plasma (BKViremia) has also been observed in renal transplant recipients with BKVN. The overall prevalence of BKViruria and BKViremia was $57 \%$ and $29 \%$, respectively. BKV replication occurs early after transplantation, mostly within the first 3 months, and can persist until the end of the first year posttransplantation in a few patients. The highest prevalence of BKViruria and BKViremia was observed at 2 and 3 months and at 3 and 6 months posttransplantation, respectively. The risk of detecting BKViremia increased when viral load in the urine was greater than $10^{4}$ copies $/ \mathrm{mL}$. BKViruria occurred within the first 3 months posttransplantation in more than $80 \%$ of these patients. The highest percentages of patients with BKViruria were observed at 2, 3, and 6 months posttransplantation, and the highest viral load in the urine at 3 and 6 months. BKViremia was detected within the first 3 months posttransplantation in $80 \%$ of patients, and in the first sample in $36 \%$ of cases. The highest percentages of BKViremia were observed at 3,6 , and 9 months posttransplantation. BKViremia disappeared before or at the same time as BKViruria.

The clinical course of individual patients varied, and the reduction of viral load did not always translate into improved graft function, probably owing to irreversible chronic allograft lesions and, also perhaps, to the con- founding effect of alloimmune injury. Buehrig et al. (18) and Drachenberg et al. (19) concluded that patients with early diagnosis had a better graft outcome with lower interstitial and tubular injuries.

\section{Risk Factors}

Conflicting information has been reported on risk factors for BKVN in renal transplant recipients. Risk factors may be donor or recipient related.

Among the risk factors that promote BKVN, immunosuppression is the most significant. The BKVN problem was practically unknown in the 1980s and early 1990s during the era of cyclosporine-based immunosuppression. The introduction of third generation immunosuppression into general clinical management has led to the current high prevalence of BKVN. Specific agents, tacrolimus and MMF, are generally believed to be associated with a higher incidence of BKVN. High-dose tacrolimus or MMF immunosuppression increases the odds ratio of developing BKVN by 13 times (20, 21). However, the single prospective trial that compared the incidence of BKViremia and BKViruria in patients randomly assigned to receive tacrolimus or cyclosporine demonstrated no significant difference between the two drugs as well as no significant association between MMF and BKVN $(22,23)$. Likewise, Hirsch et al. (24) reported the first case of BKVN in a patient treated with sirolimus and cyclosporine. Therefore, it is more plausible that patients whose immunosuppression is maintained at a higher level, rather than with a specific agent, have higher incidences of BKVN. Treatment of acute rejection with lymphocyte-depleting agents or steroid pulses is also a risk factor for BKVN (25).

$\mathrm{BKV}$ infection in the transplant recipient could be derived from either the transplant donor or the transplant recipient. In pediatric kidney transplant recipients, BKV infections were associated with a pretransplant BKV seronegative recipient, suggesting that the recipient is not the primary source of BKV (26). Hirsch et al. (27) reported that in adults, $85 \%$ of their recipients with BKVN were seropositive pretransplantation, suggesting that the high-risk group is not the seropositive donor and seronegative recipient transplant combination. On the other hand, Bohl et al. (28) demonstrated the importance of the donor kidney as the source of early BKV infection in the transplant recipient and suggested that the human leukocyte antigen (HLA) C7 allele may be an important determinant of the ability to control BKV infection in both the recipient and the donor. Indeed, recipient pairs receiving a kidney from the same donor were concordant for BKV infection, and had matched the noncoding control region and VP1 genes that tended to vary among recipients of kidneys from different donors.

Other recipient-related risk factors seem to be older age, male gender (5), Caucasian race, diabetes mellitus, acute rejection (29), and total HLA mismatches (27).

Donor-related risk factors seem to be the presence of active BKV or cytomegalovirus infection, deceased donor versus living donor transplant (30), and cold ischemia time.

\section{Diagnosis}

Histological evaluation of biopsy specimens is necessary to confirm the presence of BKV reactivation in renal transplant recipients. 


\section{Cytology}

The use of urine cytology for diagnosis of BKV infection has been documented since the 1970s. In urine, the infected cells, known as decoy cells, show rounded nuclei that are generally larger than the average transitional and tubular cells (Fig. 1). The nuclei contain viral inclusions appearing as dense granular basophilic cytoplasm with no surrounding halo. Hirsch et al. (31) reported that the positive predictive value of a "positive" decoy cell analysis to predict BKVN was $25 \%$ to $30 \%$; however, the negative predictive value was greater than $99 \%$, that is, "negative" decoy analysis means no viral nephropathy. Any further quantification of decoy cells does not provide additional clinically relevant information. Thus, the presence of decoy cells in a renal allograft recipient does not necessarily mean BKVN, but simply reactivation of the virus. Asymptomatic, urothelium shedding of viral inclusion bearing decoy cells, which are a morphological marker for viral activation, can be seen in up to $23 \%$ of healthy renal allograft recipients.

\section{Serology}

In the early 1980s, the measurement of viral hemagglutination antibodies was used to detect BKV infection. In recent years, an even more sensitive method is being used for the measurement of BKV viral load in the plasma and urine, using the polymerase chain reaction (PCR) assay.

Urine PCR analysis has a higher sensitivity but lower specificity than urine cytology. Therefore, its routine use is not helpful for the diagnosis of BKVN (32).

However, in biopsy-proven BKVN, serial quantitative PCR analysis of urine may be used to follow patients and to assess the response to therapy (29).

Recently, the measurement of messenger RNA for BKV capsid protein VP1 in urine was proposed as a noninvasive strategy to diagnose BKVN. The specificity and the sensitivity of this method were shown to be as high as $93.8 \%$ and $93.9 \%$, respectively (33), but it is not in routine use.

PCR analysis of BKV DNA in the serum is a reliable method of predicting BKV infection. The predictive value of "a positive quantitative plasma PCR test" to predict BKVN is $50 \%$ and the negative predictive value is $100 \%$ (34). The predictive power of serum PCR tests can be further enhanced by

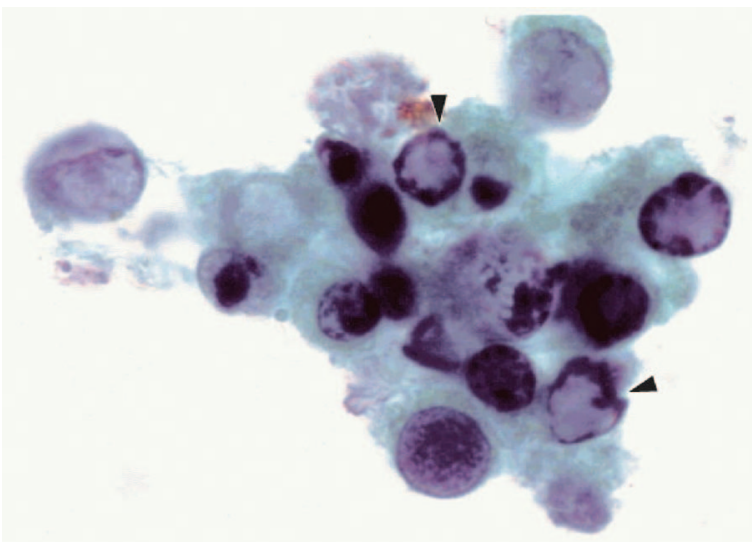

FIGURE 1. Decoy cells in urine cytology preparation showing a cluster of intranuclear viral inclusion bearing decoy cells (arrows). Papanicolaou-stained thinprep smear. the quantification of viral DNA loads. Plasma viral load levels of greater than $1 \times 10^{4}$ copies/mL have a predictive value of greater than $80 \%$.

A patient with BKV loads exceeding $1 \times 10^{4}$ copies $/ \mathrm{mL}$ in the plasma and $1 \times 10^{7}$ copies in the urine has a high risk to develop BKVN. The absence of viremia and viruria practically rules out a diagnosis of BKVN. BKViruria and BKViremia most frequently occur during the first year after renal transplantation, as asymptomatic events never leading to BKVN. Approximately $50 \%$ of the viremic episodes are transient, one-time phenomena. In some patients, persistent viremia can be seen as a prodromal stage of BKVN. But PCR assays are not standardized and protocols vary from laboratory to laboratory. The interlaboratory variability of the results can exceed $1 \log 10$.

\section{Histology}

Tissue biopsy is considered the gold standard for documentation of BKVN (35), ideally containing two cores of cortex and medulla obtained with a $15-\mathrm{G}$ needle (36). Indeed, BKVN often only focally affects renal tubules and collecting ducts and becomes eventually confluent, affecting most parenchyma (Fig. 2). Thus, the diagnosis of BKVN may be missed in $25 \%$ to $37 \%$ of biopsy samples consisting of only one small core cortex.

BKVN can present with different histologic patterns and progress through various stages. Intranuclear viral inclusion bodies in epithelial cells and virally induced tubular epithelial cell injury and lysis define BKVN in renal allograft (Fig. 3). Tubules infected by BKV show numerous cytopathic changes, including anisonucleosis of the nuclei with hyperchromasia and smudging or clumping or peripheral margination of chromatin. Infected cells have nuclei that are enlarged by 2 to 5 times, with associated N/C ratio. The most characteristic sign is the presence of basophilic intranuclear inclusions with no prominent surrounding halo and occasional ground glass appearance (31).

Three stages have been defined recently.

\section{Stage A}

Signs of viral activation are found in cortical or medullary tubular cross-sections. Viral activation is only identified by positive intranuclear immunohistochemical or in situ hybridization signals. Interstitial inflammation is absent or minimal. Tubular atrophy and interstitial fibrosis do not involve more than $10 \%$ of the biopsy sample.

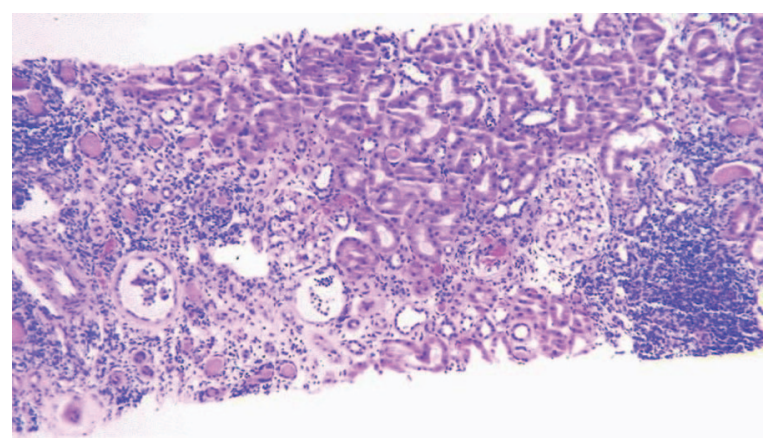

FIGURE 2. Representative histological field of BKV polyoma virus-associated nephropathy. 


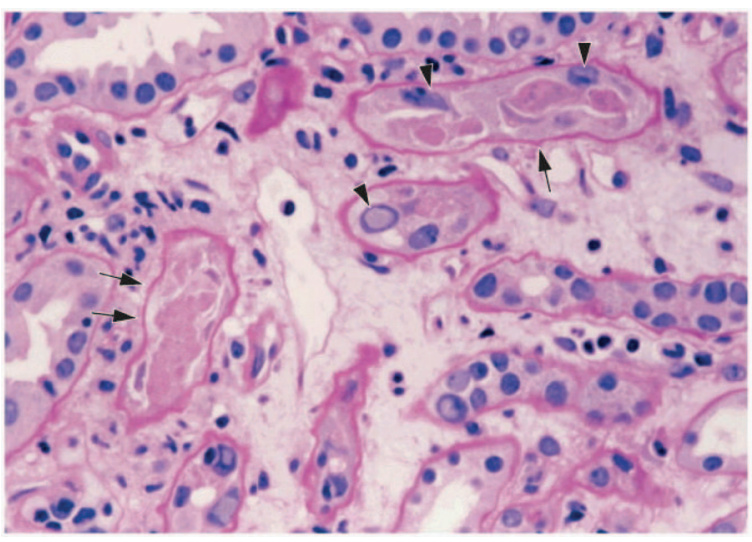

FIGURE 3. BK-virus nephropathy. The nephropathy is characterized by typical intranuclear viral inclusion bodies in tubular epithelial cells (arrowheads). Tubules show severe virally induced epithelial cell necrosis and denudation of basement membranes (arrows). Periodic acid Schiff's reagent-stained paraffin section.

Stage A is diagnosed early and responds to therapy with favorable long-term graft function and survival.

Stage B

Signs of viral activation are found in cortical and medullary tubular cross-sections with conspicuous virally induced epithelial cell lysis, denudation of tubular basement membrane and interstitial edema. Mononuclear inflammatory cell infiltrates are common. Interstitial fibrosis and tubular atrophy are minimal to moderate, remaining less than $50 \%$. Stage B is subdivided into three groups according to virally induced tubular injury or inflammation (stage B1, $\leq 25 \%$ involvement of the biopsy cores; stage B2, 26\%-49\% involvement of the biopsy cores; and stage B3, $\geq 50 \%$ involvement of biopsy cores).

Regression from stage B to stage A may be observed during the resolution of BKVN.

Stage C

Signs of viral replication are associated with tubular epithelial injury. Interstitial inflammation can vary from minimal to more important. Fibrosis and tubular atrophy injury resulting from the viral injury involve more than $50 \%$ of the tissue sample.

Fibrosis and tubular atrophy found in stage $\mathrm{C}$ are irreversible and associated with severe allograft dysfunction or loss.

Establishing the diagnosis of BKVN definitively can be challenging because not only does the histologic picture of BKVN mimic acute cellular rejection, but also both processes may be present concurrently. To distinguish acute rejection from BKVN easily, the use of tubular expression of MHCclass II (HLA DR) or C4d along peritubular capillaries is necessary. Hirsch (37) stated that immunohistochemistry using antibodies against the large T antigen of SV40 increased the sensitivity and specificity of the diagnosis. However, this test is unable to distinguish BKV from JCV or SV40 (Fig. 4). Only a minority of cases seems to coactivate BKV and JCV simultaneously. In addition to immunohistochemistry, in situ hybridization and electron microscopy can be used to confirm the diagnosis of BKVN. Ultrastructurally, polyomaviruses are

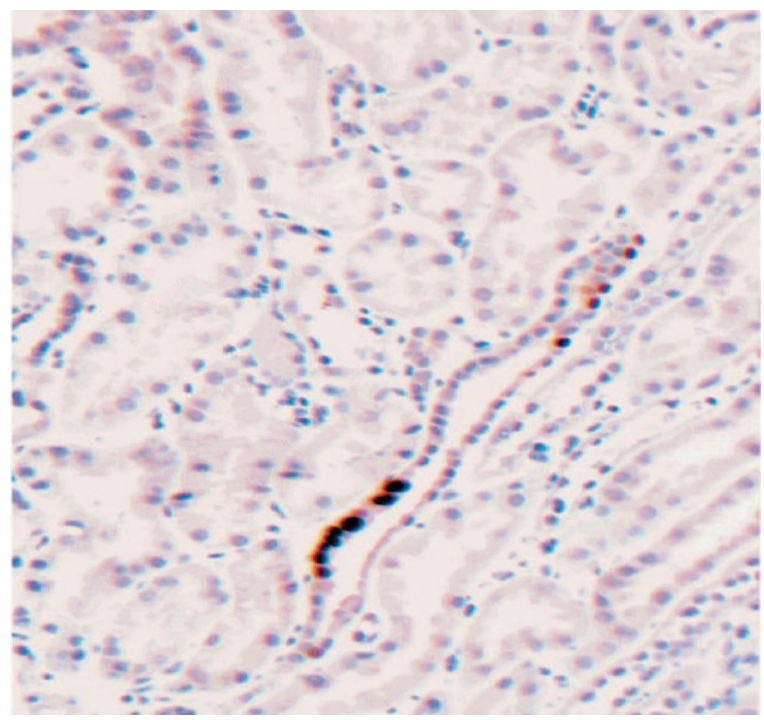

FIGURE 4. Immunohistochemical incubation on paraffinembedded tissue to detect the simian virus $40-T$ antigen $A$ positive staining reaction is seen in infected epithelial cell nuclei lining one tubule. Note the focal nature of BK-virus nephropathy.

found in nuclei as crystalloid particles of approximately 40 $\mathrm{nm}$ in diameter, distinguishing polyomaviruses from other viruses such as adenovirus or cytomegalovirus based on size.

In practice, several clinical approaches are used for early diagnosis of BKVN using urine cytology, BK viral load in urine and in blood, and finally renal allograft biopsy. Ramos et al. (38) used a screening protocol based on urine cytology. This same strategy is proposed by Hirsch et al. (27). However, Brennan et al. (23) and Ginevri et al. (26) proposed to follow BKViruria and BKViremia. The last strategy, proposed by Buehrig et al. (18), uses routine surveillance biopsies to identify patients with subclinical BKVN.

\section{Treatment}

Reduction of immunosuppression has long been a cornerstone in controlling BKV infection, but this strategy is not always curative and can put the allograft at risk of acute rejection.

In practice, the primary mode of intervention is to decrease or stop MMF. At the same time, the calcineurin inhibitor blood level is reduced to achieve a cyclosporine trough level between 100 and $150 \mathrm{ng} / \mathrm{mL}$ or a tacrolimus trough level lower than $6 \mathrm{ng} / \mathrm{mL}(18,30,38)$. The switch "tacrolimus to cyclosporine" or "tacrolimus to sirolimus" is also reported (30). But a rapid reduction in immunosuppression may result in an insufficient control of immunity, leading to acute rejection. Randhawa et al. (3) reported improved outcomes with graft loss and higher rates of viral clearance after a judicious decrease in the immunosuppressive therapy. However, in patients with progressive graft dysfunction not responding to this reduction, antiviral treatment should be considered. Antiviral drugs such as acyclovir, ganciclovir, foscarnet, and ribavirin have been shown to have no effect on the BKVN evolution. Initial case reports suggested that cytaribine, vidaribine (39), and amantadine (40) may be effective treatments 
against BKV, but subsequent experiences have not shown any benefit. Other antiviral agents such as cidofovir, leflunomide, FK778, quinolone antibiotics, and intravenous immunoglobulin $(4,40)$ are used with anecdotal success. Protocols and success rates are heterogeneous, with graft loss ranging from less than $10 \%$ to more than $80 \%$. The efficacy of these treatments is unclear, because reduction of immunosuppression has been used along with all of these strategies. However, two recent reports emphasize encouraging results, the first with very low-dose cidofovir antiviral therapy $(0.25-1 \mathrm{mg} / \mathrm{kg}$ per dose without probenecid) and the second with leflunomide.

Cidofovir is a nucleoside analogue licensed for treatment of cytomegalovirus retinitis in HIV-infected patients. Its in vitro activity spectrum encompasses papovaviruses (including the polyomavirus), adenoviruses, herpes viruses, iridiviruses, and poxviruses. The use of cidofovir is limited by its nephrotoxicity, particularly at the doses used for the treatment of systemic cytomegalovirus infection ( $5 \mathrm{mg} / \mathrm{kg}$ weekly), and therefore is contraindicated in patients with impaired renal function. In addition, proteinuria and elevation in serum creatinine were seen in $39 \%$ and $24 \%$ of patients treated with highdose cidofovir.

However, pharmacokinetic studies have demonstrated that cidofovir is highly concentrated in urine and renal tissue, the primary sites of BKV infection. Indeed, approximately $75 \%$ to $80 \%$ of the cidofovir dose is excreted in the urine unchanged within $24 \mathrm{hr}$ after administration. Kuypers et al. (41) have shown that adjuvant low-dose cidofovir therapy in addition to reduction of immunosuppression treatment has a beneficial effect in renal transplant recipients with biopsyproven BKVN. Low-dose cidofovir therapy was devoid of serious adverse effects. Eight of 21 patients with BKVN were treated with weekly adjuvant low-dose cidofovir (0.5-1.0 $\mathrm{mg} / \mathrm{kg}$ body weight) in addition to reduction of immunosuppression for a minimum of 4 and a maximum of 10 weeks. Graft function had deteriorated at the time of BKVN diagnosis but seemed to stabilize after cidofovir treatment. Blood viral load decreased in all patients after treatment and became negative in only six patients (75\%). Viral load in the urine tended to decrease but remained detectable in all patients after therapy. However, 9 of 13 recipients who received no adjuvant cidofovir therapy lost their graft within the year after diagnosis of BKVN. Blood viral load decreased initially and became negative in only six patients $(46 \%)$. This report and others (42-44) confirm that adjuvant cidofovir treatment results in an improved clinical course and in a blood viral load reduction in most patients. These preliminary results are encouraging but must be confirmed by a randomized controlled study to prospectively evaluate the effect of cidofovir on graft function, graft survival, and viral load compared with a reduction of immunosuppression.

Leflunomide is an immune suppressant drug, used for the treatment of rheumatoid arthritis. More recently, it has been advocated as an immunosuppressive agent after kidney transplantation to allow reduction in the dose of nephrotoxic drugs, to retard the development of chronic rejection and to protect against viral infections, including cytomegalovirus, herpesvirus, and BKV. Leflunomide is rapidly metabolized to A77 1726, its active metabolite. Its mechanism of action seems to involve the inhibition of a mitochondrial enzyme necessary for orotate synthesis in the de novo pathway to uridine, and the inhibition of certain tyrosine kinases involved in T-cell and B-cell signaling cascades. Josephson et al. (45) studied 26 patients with biopsy-proven BKVN. In all patients, MMF was stopped at the time leflunomide was started. The daily maintenance dose of leflunomide was 40 $\mathrm{mg}$ after a loading dose of $100 \mathrm{mg}$ per day during 5 days. Tacrolimus trough levels were maintained at 4 to $6 \mathrm{ng} / \mathrm{mL}$. Leflunomide treatment of patients with BKVN reduces BKV load in blood and in urine and prevents reoccurrence of the nephropathy. Only 4 of 26 BKVN recipients lost their renal graft $(15 \%)$ during this study. Leflunomide blood levels above $40 \mu \mathrm{g} / \mathrm{mL}$ were necessary for antiviral action. No serious adverse event was reported in this article. As is the case for cidofovir, a randomized controlled study comparing leflunomide and immunosuppressive reduction must confirm this preliminary study.

Fluoroquinolone antibiotics seem to inhibit BK viral replication in vitro. Recently, five clinically relevant fluoroquinolones (gatifloxacin, ofloxacin, ciprofloxacin, trovofloxacin, and levofloxacin) were tested and demonstrated their ability to inhibit viral replication SV40 in permissive monkey's cells $(46,47)$. A recent study showed the positive effect of a short course of gatifloxacin (500 mg orally once daily) on renal transplant recipients excreting BKV in urine (48). Moreover, exposure to ciprofloxacine seems to decrease the BKV load in another study reported in bone marrow transplant recipients (49). Again prospective randomized studies are necessary to evaluate this antiviral action.

\section{Outcome of Infection}

Specific antiviral strategies to treat patients with BKVN are thus poorly defined. In most cases, BKVN was treated by reduction of immunosuppressive therapy and sometimes additionally antiviral drugs (currently cidofovir or leflunomide). Graft loss as a result of BKV reactivation varies in many reports from $45 \%$ (4) to $67 \%$ (3). The timing for the initial diagnosis of BKVN is critical for therapeutic success and good outcome. A level of renal dysfunction defined as serum creatinine more than $2.2 \mathrm{mg} / \mathrm{dL}$ at the time of diagnosis of BKVN was correlated with poorer long-term graft survival (30).

BKVN seems to be an indicator of intense or overimmunosuppression. Prevention of BKVN may be a better strategy than treatment of BKV infection. A therapeutic intervention may already be initiated when patients present significant signs of BK viral reactivation but lack histologic proof of BKVN. BKViremia is commonly absent and may serve as the earliest indicator of overimmunosuppression. Brennan et al. (23) have prevented the progression of $\mathrm{BKVN}$ in a large cohort of patients with prospective monitoring of urine and blood BK viral load, and preemptive withdrawal of the antimetabolite agent on development of BKViremia and BKViruria. Another study showed a resolution or a decrease of BKViruria or viremia only with reduction of immunosuppressive standard drugs (50).

\section{Retransplantation}

Retransplantation after BKVN has been reported in some cases with recurrence of the disease in only approximately $12 \%$ of all patients (50). This favorable outcome after retransplantation may be caused by the presence of HLA C7 in the second transplant $(35,50,51)$. The allograft nephrec- 
tomy did not protect against the recurrence of BKVN (52). Intense immunosuppression and retransplantation during BKV replication should be avoided. BKV blood viral load must be as low as possible.

Preemptive retransplantation is possible if immunosuppressive treatment is reduced in patients at both 40 and 12 weeks before retransplantation. This period is necessary to decrease the BKV plasma loads. Since latent BKV remain a source of reinfection in autologous kidney and bladder tissue, the notion that nephrectomy is unnecessary disregards the HLA-dependent differences in antiviral immune control, as the latter is likely to be more effective in autologous as compared to allogenic tissue. But, after graft nephrectomy, changes in BKV loads are more easily attributed at the new transplant (52).

\section{CONCLUSIONS}

BKVN has become an important problem in renal transplantation because of more powerful immunosuppressive strategies. Its development confers a poor prognosis for renal graft survival and an early diagnosis is necessary to achieve favorable outcome. The presence of BKVN suspected by BK viral load in urine and blood must be proved by renal biopsy. However, efficient treatment is still a great challenge to nephrologists. A quick reduction in the immunosuppressive treatment is the first step. Other treatments still need validation.

\section{REFERENCES}

1. Gardner SD, Mackenzie EF, Smith C. Prospective study of the human polyomavirus BK and JC and cytomegalovirus in renal transplant recipients. J Clin Pathol 1984; 37: 578.

2. Gardner SD, Field AM, Coleman DV. New human papovavirus (BK) isolated from urine after renal transplantation. Lancet 1971; 1: 1253.

3. Randhawa PS, Finkelstein S, Scantlebury V. Human polyoma-virusassociated interstitial nephritis in the allograft kidney. Transplantation 1999; 67: 103.

4. Nickeleit V, Hirsch HH, Zeiler M. BK-virus nephropathy in renal transplants-tubular necrosis, MHC-class II expression and rejection in a puzzling game. Nephrol Dial Transplant 2000; 15: 324.

5. Ramos E, Darchenberg CB, Papadimitriou JC, et al. Clinical course of polyoma virus nephropathy in 67 renal transplant patients. J Am Soc Nephrol 2002; 13: 2145.

6. Barbanti-Brodano G, Sabbioni S, Martini F, et al. Simian virus 40 infection in humans and association with human disease: Results and hypotheses. Virology 2004; 318: 1 .

7. Geetha D, Tong BC, Racusen L. Bladder carcinoma in a transplant recipient: Evidence to implicate the BK human polyomavirus as a causal transforming agent. Transplantation 2002; 73: 1933.

8. Moret H, Ingrand D. Les polyomavirus humains. Médecine Thérapeutique 1997; 6: 473

9. Dugan AS, Eash S, Atwood W. Update on BK virus entry and intracellular trafficking. Transpl Infect Dis 2006; 8: 62.

10. Knowles WA, Pipkin P, Andrews N, et al. Population-based study of antibody to the human polyomaviruses BKV and JCV and the simian polyomavirus SV40. J Med Virol 2003; 71: 115.

11. Shah KV, Daniel R, Warszawski R. High prevalence of antibodies to BK virus, an SV40-related papovavirus, in residents of Maryland. J Infect Dis 1973; 128: 784.

12. Hirsch HH, Steiger J. Polyomavirus BK. Lancet Infect Dis 2003; 3: 611.

13. Boubenider S, Hiesse C, Marchand S. Post transplantation polyomavirus infection. J Nephrol 1999; 12: 24.

14. Colvin RB, Mauiyyedi S. Differential diagnosis between infection and rejection in renal allografts. Transplant Proc 2001; 33: 1778.

15. Ahuja M, Cohen EP, Dayer AM, et al. Polyomavirus infection after renal transplantation. Use of immunostaining as a guide to diagnosis. Transplantation 2001; 71: 896.
16. Sachdeva M, Nada R, Jha V, et al. The high incidence of BK polyoma virus infection among renal transplant recipients in India. Transplantation 2004; 77: 429.

17. Bressollette-Bodin C, Coste-Burel M, Hourmant M, et al. A prospective longitudinal study of BK virus infection in 104 renal transplant recipients. Am J Transplant 2005; 5: 1926.

18. Buehrig CK, Lager DJ, Stegall MD. Influence of surveillance renal allograft biopsy on diagnosis and prognosis of polyomavirus-associated nephropathy. Kidney Int 2003; 64: 665.

19. Drachenberg CB, Papadimitriou JC, Wali R. Improved outcome of polyoma virus allograft nephropathy with early biopsy. Transplant Proc 2004; 36: 758.

20. Binet I, Nickeleit V, Hirsch HH. Polyomavirus disease under new immunosuppressive drugs: A cause of renal graft dysfunction and graft loss. Transplantation 1999; 67: 918.

21. Mengel M, Marwedel M, Radermacher J. Incidence of polyomavirusnephropathy in renal allografts: Influence of modern immunosuppressive drugs. Nephrol Dial Transplant 2003; 18: 1190.

22. Lopez-Rocafort L, Wang C, Miller B. A prospective evaluation of BK virus infection in renal transplant patients [Abstract]. Am J Transplant 2002; 2: S260.

23. Brennan DC, Agha I, Bohl DL, et al. Incidence of BK with tacrolimus versus cyclosporine and impact of preemptive immunosuppression reduction. Am J Transplant 2005; 5: 582.

24. Hirsch HH, Mohaupt M, Klimkait T. Prospective monitoring of BK virus load after discontinuing sirolimus in a renal transplant patient with BK virus nephropathy. J Infect Dis 2001; 184: 1494.

25. Moens V, Subramaniam N, Johansen B. A steroid hormone response unit in the late leader of the noncoding control region of the human polyomavirus BK confers enhanced host cell permissivity. J Virol 1994; 68: 2393 .

26. Ginevri F, De Santis R, Comoli P, et al. Polyomavirus BK infection in pediatric kidney-allograft recipients: A single analysis of incidence, risk factors, and novel therapeutic approaches. Transplantation 2003; 75 : 1266.

27. Hirsch HH, Knowles W, Dickenmann M. Prospective study of polyomavirus type BK replication and nephropathy in renal-transplant recipients. N Engl J Med 2002; 347: 488.

28. Bohl DL, Storch GA, Ryschkewitsch C, et al. Donor origin of BK virus in renal transplantation and role of HLA C7 in susceptibility to sustained BK viremia. Am J Transplant 2005; 5: 2213.

29. Merlino C, Bergallo M, Gribaudo G. Polyomavirus BK DNA quantification assay to evaluate viral load in renal transplant recipients. J Clin Virol 2003; 28: 265.

30. Vasudev B, Hariharan S, Hussain SA, et al. BK virus nephritis: Risk factors, timing, and outcome in renal transplant recipients. Kidney Int 2005; 68: 1834

31. Nickeleit V, Hirsch HH, Binet IF. Polyomavirus infection of renal allograft recipients: From latent infection to manifest disease. J Am Soc Nephrol 1999; 10: 1080.

32. Holman CJ, Van Burik JA, Hinrichs SH. Specific detection of human BK polyomavirus in urine samples of immunocompromised patients. Clin Diagn Lab Immunol 2003; 10: 66.

33. Ding R, Medeiros M, Dadhania D. Non invasive diagnosis of $B K$ virus nephritis by measurement of messenger RNA for BK VP1 in urine. Transplantation 2002; 74: 987.

34. Nickeleit V, Klimkait T, Binet IF. Testing for polyomavirus type BK DNA in plasma to identify renal-allograft recipients with viral nephropathy. N Engl J Med 2000; 342: 1309.

35. Hirsch HH, Brennan DC, Drachenberg CB, et al. Polyomavirus-associated nephropathy in renal transplantation: Interdisciplinary analyses and recommendations. Transplantation 2005; 79: 1277.

36. Drachenberg CB, Papadimitriou JC, Hirsch HH, et al. Histological patterns of polyomavirus nephropathy: Correlation with graft outcome and viral load. Am J Transplant 2004; 4: 2082.

37. Hirsch HH. Polyomavirus BK nephropathy: A (re-)emerging complication in renal transplantation. Am J Transplant 2002; 2: 25.

38. Ramos E, Drachenberg CB, Portocarrero M, et al. BK virus nephropathy diagnosis and treatment: Experience at the university of Maryland renal transplant program. Clinical Transplants, 2002, Chapter 12:143.

39. Chapman C, Flower AJ, Durrant ST. The use of vidarabine in the treatment of human polyomavirus associated acute haemorrhagic cystitis. Bone Marrow Transplant 1991; 7: 481. 
40. Sener A, House AA, Jevnikar AM, et al. Intravenous immunoglobulin as a treatment for BK virus associated nephropathy: One-year follow-up of renal allograft recipients. Transplantation 2006; 81: 117.

41. Kuypers DRJ, Vandooren AK, Lerut E, et al. Adjuvant low-dose cidofovir therapy for BK polyomavirus interstitial nephritis in renal transplant recipients. Am J Transplant 2005; 5: 1997.

42. Vats AM, Saxena M, Randhawa P. Role of quantitative viral load and cidofovir therapy in the management of BK virus nephropathy [Abstract]. J Am Soc Nephrol 2001; 12: 950.

43. Vats A, Shapiro R, Randhawa PS. Quantitative viral load monitoring and cidofovir therapy for the management of BK virus-associated nephropathy in children and adults. Transplantation 2003; 75: 105.

44. Araya CE, Lew JF, Fennel RS, et al. Intermediate-dose cidofovir without probenecid in the treatment of BK virus allograft nephropathy. Pediatr Transplantation 2006; 10: 32.

45. Josephson MA, Gillen D, Javaid B, et al. Treatment of renal allograft polyoma BK virus infection with leflunomide. Transplantation 2006; 81: 704 .
46. Randhawa PS. Anti-BK virus activity of ciprofloxacin and related antibiotics. Clin Infect Dis 2005; 41: 1366.

47. Ali S, Chandraker A, Decaprio J. Inhibition of polyoma helicase activity by quinolones. J Am Soc Nephrol 2003;14: 43A.

48. Chandraker A, Ali S, Drachenberg CB, et al. Use of fluoroquinolones to treat BK infection in renal transplant recipients. Am J Transplant 2004; 4(suppl 8): 587 [abstract 1564].

49. Leung AYH, Chan MTL, Yuen KY, et al. Ciprofloxacin decreased polyoma BK virus load in patients who underwent allogeneic hematopoietic stem cell transplantation. Clin Infect Dis 2005; 40: 528.

50. Ramos E, Vincenti F, Lu WX. Retransplantation in patients with graft loss caused by polyoma virus nephropathy. Transplantation 2004; 77: 131.

51. Ginevri F, Pastorino N, De Santis R, et al. Retransplantation after kidney graft loss due to polyomavirus BK virus nephropathy: Successful outcome without original allograft nephrectomy. Am J Kidney Dis 2004; 42: 821.

52. Hirsch HH, Ramos E. Retransplantation after polyomavirus-associated nephropathy: Just do it? Am J Transplant 2006; 6: 7. 